\title{
Fear and Fitness: An Evolutionary Analysis of Anxiety Disorders
}

\author{
Isaac M. Marks \\ Institute of Psychiatry, London \\ Randolph M. Nesse \\ University of Michigan Medical School, Department of Psychiatry, Ann Arbor
}

\begin{abstract}
This article reviews the evolutionary origins and functions of the capacity for anxiety, and relevant clinical and research issues. Normal anxiety is an emotion that helps organisms defend against a wide variety of threats. There is a general capacity for normal defensive arousal, and subtypes of normal anxiety protect against particular kinds of threats. These normal subtypes correspond somewhat to mild forms of various anxiety disorders. Anxiety disorders arise from dysregulation of normal defensive responses, raising the possibility of a hypophobic disorder (too little anxiety). If a drug were discovered that abolished all defensive anxiety, it could do harm as well as good. Factors that have shaped anxiety-regulation mechanisms can explain prepotent and prepared tendencies to associate anxiety more quickly with certain cues than with others. These tendencies lead to excess fear of largely archaic dangers, like snakes, and too little fear of new threats, like cars. An understanding of the evolutionary origins, functions, and mechanisms of anxiety suggests new questions about anxiety disorders.
\end{abstract}

KEY WORDS: Fear, phobias, anxiety disorders, obsessive-compulsive disorder, agoraphobia, social phobia, prepotency, preparedncss

\section{INTRODUCTION}

Nearly everyone recognizes that anxiety is a useful trait that has been shaped by natural selection. Even good things, however, cease to be good when they become excessive. Too much anxiety can be disabling. If a drug were found that abolished all anxiety for all time it could be as harmful as a drug that

Received January 23, 1994; revised September 17, 1994.

Address reprint requests and correspondence to: Isaac M. Marks, M.D., Institute of Psychiatry, London, SE5 8AF, U.K., or to Randolph M. Nesse, M.D., The University of Michigan Medical School, Department of Psychiatry, C440, Med-Inn Bldg., Ann Arbor, MI 48109-0840, U.S.A. E-mail: Nesse@um.cc.umich.edu 
induced anxiety of crippling degree. Adaptive modulation is the keynote to success. This point is best understood from an evolutionary perspective on the origins and functions of anxiety. Such a framework can illuminate current clinical and research issues.

Anxiety is one kind of emotion. Why do emotions play such a central part in our lives? Many researchers now view emotions as response patterns shaped by natural selection to offer selective advantages in certain situations (Plutchik and Kellerman 1980; Marks 1987; Lelliott et al. 1989). The bodily, behavioral, and cognitive responses that constitute emotions are a preprogrammed pattern of responses that increase ability to cope with threats or seize opportunities.

Each emotion can be thought of as a computer program designed to accomplish some specific fitness task particularly well (Nesse 1990). If the current task is courtship, romantic love is helpful. If one is being betrayed, anger is useful. If a tiger is attacking, then fearful flight and avoidance are best. If people are disapproving, then social anxiety may be appropriate. Different emotions, however, must be orchestrated, just as endocrine function must be coordinated in an endocrine orchestra. Emotional responses must fit changing adaptive challenges, with each emotion fitting a particular kind of situation.

Anxiety increases fitness in dangerous situations which threaten a loss of reproductive resources. Such resources include not only life and health, but also relationships, property, status, reputation, skill, and anything else that could increase Darwinian fitness. Given this function of anxiety, we would expect it to be aroused by any cues that indicate a risk of loss. If each subtype of anxiety evolved to deal with a particular kind of danger (as we will suggest), then the features of each anxicty subtypc and the signals that arouse it should match the corresponding danger.

\section{Prior Work on Evolution and Anxiety}

The utility of fear and anxiety has long been recognized. Darwin's book on emotions emphasized the communication aspect of fear (Darwin 1872). The function of separation anxiety was pointed out by Bowlby (1973), Marks (1987), Ainsworth (Ainsworth et al. 1978), Klein (1981, p. 248), and many others. The adaptive functions of components of the stress response were laid out long ago by Cannon (1929) and later by Frankenhaeuser (Konner 1990). It has also long been known that fear is more easily linked to certain cues than to others (Marks 1969; Seligman 1970; Paley 1970 [1802]; Ruse 1988; Mineka et al. 1980).

We still lack, however, a systematic analysis of the evolutionary origins and functions of anxiety. Little research has demonstrated the advantages of anxiety, and almost no one has looked for disorders characterized by too little anxiety. There are several reasons for these gaps in our knowledge. Most writings on the functions of anxiety apologize about "speculatively" addressing such "teleological" issues, even though biologists have known for 30 years that questions about the evolutionary function of a trait are not teleological at 
all and that hypotheses about such functions can be tested just like any others (Mayr 1974). Complex traits can be shaped by natural selection only if they serve functions that increase fitness. Hypotheses about these functions are not matters for speculation but for clear formulation and rigorous testing.

Testing of evolutionary hypotheses is now the focus of most research into animal behavior (Alcock 1989), especially by behavioral ecologists (Krebs and Davies 1991), who emphasize the functional significance of behavior, not just the descriptions dwelt on by earlier ethologists. These methods are only just beginning to be applied to the study of human behavior (Howard 1991; Barkow et al. 1992; Smith 1982). Therefore, few data-based studies of humans are available as yet. By highlighting the value of this approach and its clinical and research significance, we hope to encourage work on human anxiety that builds on the models provided by behavioral ecology. Even before then, we suggest that this perspective can provide some guidance in answering current questions about anxiety and its disorders.

\section{Subtypes of Anxiety}

A question of major concern is how to split (or lump) the various kinds of anxiety disorders, and how to justify the taxonomy. Some researchers emphasize the similarities of all anxieties and postulate the unity of all anxiety disorders. Others stress the differences between different kinds of anxiety, positing several distinct disorders, each with its own etiology, phenomenology, and treatment. An evolutionary perspective suggests a middle ground between these two extremes. General anxiety probably evolved to deal with threats whose nature could not be defined very clearly. Subtypes of anxiety probably evolved to give a selective advantage of better protection against a particular kind of danger.

To illustrate this, consider another defense, the immune response. Humans have a capacity for both a general immune response and for specialized immune responses. Antigens arouse general responses, such as lymphocyte monitoring for the presence of foreign material, inflammation, fever, pain, and malaise. They also arouse specific responses, such as immunoglobulins to bacterial infection, interferon to viral invasion, eosinophils to parasites, and natural killer cells to cancer.

Like antigens, other external threats also arouse both general and more specific responses. General threats arouse general anxiety-inducing vigilance, physiological arousal, and planning for defense. Specific threats elicit specific patterns of behavioral defense (Edmunds 1974; Janzen 1981). High places evoke freezing; social threats arouse submission; predators provoke Hight. An evolutionary view suggests that different types of fear should share many aspects because reactions (e.g., rise in heart rate) that are useful in one kind of danger are likely to also help other kinds. Furthermore, the presence of one threat makes it likely that others are present too. A hunter-gatherer who is excluded from the group becomes more vulnerable not only to predators but 
also to starvation, climatic extremes, and falling off cliffs and into holes in unknown territory.

The utility of different kinds of anxiety depends in part on the four ways in which anxiety can give protection (Marks 1987). Two of them parallel the body's ways of dealing with foreign material: (1) Escape (flight) or avoidance (preflight) distances an individual from certain threats in the way that vomiting, disgust, diarrhea, coughing, and sneezing put physical space between the organism and a pathogen. (2) Aggressive defense (anger, clawing, biting, or spraying with noxious substances) harms the source of the danger just as the immune system attacks bacteria. (3) Freezing/immobility may benefit by (a) aiding location and assessment of the danger, (b) concealment, and (c) inhibiting the predator's attack reflex. (4) Submission/appeasement is useful when the threat comes from one's own group. Inhibition of impulses probably fits best under this category.

Multiple strategies can, of course, be used together. Squid escape by jet propulsion in a cloud of concealing ink. Puffer fish look ferocious, and their spines harm the predator's mouth. Agoraphobics freeze in panic and then dash for home. Social phobics avoid or escape from authority figures if they can, and submit if they cannot. Obsessive-compulsives avoid "contamination" if possible; if they can't, they try to escape from it by washing. Any of the above four strategies can involve deception (Krebs and Dawkins 1984). An escaping rabbit runs straight ahead, but then circles furtively behind the pursuer. When a cat is threatened, its fur stands on end, making it seem larger. A possum plays dead.

In summary, the anxiety subtypes probably exist because of the benefits of having responses specialized to deal with particular dangers, but it is unlikely that anxiety subtypes have differentiated into completely unrelated response patterns. To the extent that various anxiety disorders are exaggerations of various subtypes of normal anxiety, anxiety disorders can likewise be expected to be partially, not fully, differentiated.

\section{The Relationship Between General Anxiety and Panic}

Can an evolutionary perspective illuminate the relationship between general anxiety and panic? Are anxiety and panic separate, or on a continuum? Mild threat causes a general increase in anxiety that helps to locate the source and type of danger and to plan possible ways to deal with it. Extreme or sudden danger is more likely to produce panic. General anxiety commonly precedes panic. A similar relationship is observed with the two related defenses of nausea and vomiting. Nausea stops one from eating (useful if the food being ingested is toxic), and leads one to avoid foods that induced nausea (also useful). Extreme nausea culminates in vomiting, which expels the contents of the stomach. Occasionally there can be projectile vomiting without preceding nausea, just as there can be sudden panic without preceding anxiety.

Many components of the anxiety and panic response are those which 
Cannon recognized as useful in situations in which "fight or flight" are the adaptive responses (Cannon, 1929). Cannon noted the functions of many of these components. Epinephrine acts on platelet beta receptors to enhance clotting and on the liver to release glucose. Cardiovascular changes speed blood circulation. Circulation patterns change so that less blood goes to the skin and gut, and more to the muscles. Hyperventilation raises oxygen import and carbon dioxide export. Sweating cools the body and makes it slippery. A sense of imminent doom galvanizes preventive action and forestalls dawdling. These components form a reliable constellation in the anxiety/panic response, which is partly mediated by adrenergic receptors (a proximate explanation). They act together to increase fitness in the face of danger (the evolutionary explanation that is needed in addition to the proximate one).

These aspects of anxiety and panic are largely similar whether cued by heights, animals, thunderstorms, darkness, public places, separation, or social scrutiny. Their similarity reflects the value of this defense against a wide array of threats.

\section{Other Subtypes of Anxiety and Specific Threats}

The features of many anxiety subtypes are well matched to the task of defending against particular types of threats. On the hypothesis that anxiety disorders represent extremes of normal forms of anxiety, we will not distinguish here between normal and pathological states.

1. Fear:

a. Heights induce freezing instead of wild flight, thus making one less liable to fall.

b. Blood or injury cues produce a diphasic vasovagal response ending in bradycardic syncope. Such fainting may reduce blood loss after injury and, like death feigning, inhibit further attack by a predator (Marks 1988).

c. Public places and being far from home arouse a cluster of mild fears that guard against the many dangers encountered outside the home range of any territorial species. Agoraphobia can be seen as an intensification of such extraterritorial fear (Nesse 1987; Lelliott et al. 1989).

d. Traumas are followed by fear and avoidance of anything reminiscent of the original trauma. A natural tendency to such seeming "overreaction" is understandable given the high cost of failure to avoid any possibility of reexperiencing a mortal danger.

e. Social threats evoke responses that promote group acceptance, for example, submission to dominants and to norms of dress, mien, odor, speech, customs, beliefs. This prevents dangerous extrusion from the group. Mild shyness and embarrassment can promote acceptance. If shyness and embarrassment are excessive, however, then fitness suffers, as in several anxiety disorders: pervasive shyness in avoidant personality disorder; gaze aversion and fear of scrutiny, of shaking, and of blushing in social 
phobia; fear of excreting near others in sphincteric phobias (Marks 1987, pp. 362-371); terror of looking or smelling abnormal in dysmorphophobia; fear of behaving antisocially in obsessive-compulsive disorder. Impulses to behave in ways that would cause social rejection may arouse general anxiety without the subject being aware of those punishable impulses, thus helping to conceal them from others (Nesse 1990). We do not emphasize a distinction between fear of specific dangers and anxiety aroused by nonspecific dangers or unconscious impulses, because in all cases the state, whether anxiety or fear, is aroused by a cue that indicates a threat to reproductive resources.

\section{Fear-like Patterns:}

Some threats evoke specific discomforts not usually called anxiety.

a. Food aversions are conditioned much less easily to anxiety and to pain than to nausea and vomiting.

b. Threat of losing one's mate to a rival evokes jealousy that includes not only anxiety but also seeking of reassurance and aggression to try to avert loss. This pattern is intensified in morbid jealousy, which often includes obsessive ruminations and ritualistic checking on possible infidelity of the partner.

c. The normal gag reflex stops material entering the upper respiratory tract. Hypersensitivity of this reflex may cause undue gagging with intense pharyngeal discomfort (Wilks and Marks 1983).

3. Obsessive-compulsive (OC) behaviors

The anxiety and sense of compulsion in obsessive-compulsive disorder (OCD) may be a caricature of the motivational mechanisms that drive and prioritize normal behavioral routines. Such routines are parodied by $\mathrm{OC}$ rituals, which distort priorities.

a. Many behavioral sequences are best completed to their functional end; if left unfinished, time and energy are likely to be wasted. Tension motivates persistence until closure is effected. Many obsessive-compulsives seem to lack the "fiat" we experience that marks the end of one sequence of thoughts or actions (James 1893). Such patients feel tense and must continue repeating thoughts or actions until they "feel right."

b. Many behavioral sequences are best executed one at a time, otherwise energy may be frittered away on disparate tasks, none of which are completed. The excess orderliness of OCD also wastes energy by doing tasks one by one to perfection, regardless of their importance, while leaving vital tasks undone.

c. Parasitism and infection are reduced in mammals by grooming and in birds by preening (Hart 1990). In Inany primate species, grooming also smoothes social interaction as when a defeated baboon grooms the victor intensely after a fight. Many obsessive-compulsives wash and groom endlessly; if not allowed to do this, they often feel disgust or other discomfort rather than anxiety.

d. Group membership requires attention to others' needs. Disregard of these 
makes ostracism likely. In OCD, there is maladaptive overconcern with the risk of harming others.

e. Hoarding guards against future shortages and is protective in environments of scarcity. It is grotesquely exaggerated in some obsessive compulsives.

It is unclear why obsessive-compulsives explain (rationalize) their fears and rituals in a more complex manner than do phobics. Perhaps different cognitive mechanisms are deranged in obsessive-compulsives as compared to phobics.

To summarize this section, the features of anxiety disorder subtypes largely correspond to various dangers humans have faced during their evolution. As noted above, subtypes of anxiety are not completely distinct because multiple threats are common, and because so many aspects of anxiety defend against many, not just one, kinds of danger. The most recent genetic evidence is consistent with this view. A study of 2,163 female twin pairs concludes: "[W]e found strong evidence of the existence both of genetic and environmental risk factors unique to each kind of phobia and for genetic and environmental risk factors that infiuenced all phobia subtypes. Our results were midway between the two extreme hypotheses regarding the interrelationship of the subtypes of phobias: (1) the subtypes of phobias are distinct, unrelated syndromes and (2) the subtypes of phobias represent minor variations of a single disorder." (Kendler 1992, p. 279).

It should be possible to create a taxonomy for anxiety disorders that reflects the origin and functions of normal anxieties. Just as various components of the normal immune response can respond too much (anaphylaxis), too little (hypoimmune disorders), or to the wrong cue (allergy) or wrong target (autoimmune disease), so anxiety can be excessive (as in general anxiety or panic disorder), deficient (hypophobia), or in response to a stimulus that is not dangerous (simple/specific phobias). The immune disorders are being unraveled by increasing understanding of the normal functions and mechanisms of the immune system. The anxiety disorders will also make more sense as we learn about the normal functions of the components of the anxiety system and the mechanisms that mediate them.

\section{Defense Regulation}

Defenses enhance survival only when appropriate to the degree and type of threat. If a defense is deficient, excessive, or inappropriate in form, then fitness suffers. People who lack the capacity for pain die young because their tissues get damaged (Stevens 1981); those with excessive pain are also disabled. Suppressing the cough reflex makes pneumonia likely; too much coughing can cause cerebral hemorrhage. Stopping vomiting or diarrhea may lead to death by toxin absorption (DuPont and Hornick 1973); too much vomiting or diarrhea can kill by dehydration. The systems that regulate these defenses have been finetuned to detect the form and amount of threat and respond appropriately. 
Anxiety, too, is beneficial only if carefully regulated. Too much disables. Too little anxiety leads to behavior that makes us more likely to fall off a cliff, be attacked by a wild beast, hurt by other humans, or to act in ways that lead to social exclusion. People with too little anxiety do not come to psychiatrists complaining of deficient fear, so their disorders, the "hypophobias," still await formal description.

The regulation of anxiety is an example of the benefit-cost tradeoffs that make every organism "a bundle of selective compromises" (Alexander 1975). While a grazing deer that lifts its head every few seconds to scan for predators has less time to eat, mate, and care for offspring, one that lifts its head too little may eat more, but is at greater risk of being eaten itself. How are such factors balanced?

The law of diminishing returns applies to anxiety, as to so much else. A little anxiety may yield marked protective gains but more fear may not be worth the costs. Selection pressure for fearfulness tapers off at the point where the incremental cost of further fear starts to rise above the incremental protection it yields. Evolved defenses often seem over-responsive (Marks 1987) because repeated false alarms may cost less than a single failure to respond when the danger is great (Nesse 1990). Anxiety at the mere hint of danger is therefore common, even though it may appear needless to a casual observer. Because the costs of erring on the side of caution are usually less than those of risk taking, it is no wonder that anxiety disorders are frequent.

Different environments select for different degrees of fear. On long-isolated islands, without predators many species lost their tendency to flee, fight, or hide. When humans arrived and brought in predators, the tame indigenous species were often killed off rapidly. The point is captured in the phrase "Dead as a dodo."

\section{Regulation of Anxiety by Cues of Danger}

It would be grossly inefficient to become anxious only after actual pain or loss. Instead, the nervous system has been shaped so that anxiety arises in response to cues that denote potential threats. Most of the dangers an individual is likely to encounter have already been survived by its forebears. Individuals who recognized and responded to a hint of such threats lived longer and had more descendants than those who had to learn from bitter experience. Selection thereby shaped a nervous system that makes us attend intently to certain cues - this is prepotency (Marks 1969; Ohman and Dimberg 1984) or salience. For instance, snake- or eye-like patterns arouse anxiety more easily than do other patterns. We are also predisposed to learn certain reactions to certain stimuli-this is preparedness (Seligman 1970). For instance, heights and snakes evoke fear rather than nausea, while bad food produces nausea rather than fear. Prepotent attention to particular patterns of stimulation is the first step on the path to prepared reactions to those patterns.

Fear develops quickly to minimal cues that reflect ancient dangers. As 
with imprinting, where experience inscribes the precise parental features that the offspring recognizes, so it is often better to convey the specifics of danger by rapid learning than by rigid genetic encoding. This avoids wasteful defense against safe stimuli. African plains' animals are less fearful of predators' presence per se than of their approach, their hunting intent, and other signs of danger (Marks 1987).

Prepared rapid learning of fear is partly mediated by the reactions of caretakers and peers. Keen observation and imitation of them is itself a prepared response. When an infant sees a visual cliff or a stranger, it looks at mother frequently to monitor her response (Marks 1987). If she smiles, this reassures; if she shows alarm, this augments her baby's fear. Rhesus monkeys are born without snake fear. Enduring fear develops after a few observations of another rhesus taking fright at a snake, but not after seeing it take the same fright at a flower (Mineka et al. 1984). Likewise, a fawn is not born with fear of a wolf, but lifelong panic is conditioned by seeing its mother flee just once from a wolf.

Prepared fears tend to manifest at the age when they become adaptive (Marks 1987). Height fear emerges in infants shortly before they start crawling at six months (Scarr and Salapatek 1970) and rises with crawling experience (Berthenthal et al. 1983). As the two-year-old child explores further atield, animal fears emerge. As young people leave home, agoraphobia arises.

Both prepotency and preparedness lead to a nonrandom distribution of fears (Marks 1987). Stimuli that come to be feared are mostly ancient threats: snakes, spiders, heights, storms, thunder, lightning, darkness, blood, strangers, social scrutiny, separation, and leaving the home range. Most phobias are exaggerations of these natural fears.

Unlike the prepared fears and phobias just noted, we rarely fear cues that have been harmless in our past, for example, wood, leaves, flowers, stones, or shallow water. Aversion therapists found it hard to induce fear of alcohol in alcoholics, or of women's clothes in transvestites (Gelder and Marks 1970). Nor do we easily develop fear of evolutionarily recent dangers (Cook et al. 1986). Few fear motor cars, guns, cigarettes, or alcohol, despite knowing that these now kill far more people than do snakes, spiders, or sharks. Not having been present long enough to materially alter our genetic endowment, such modern perils are feared too little. It is difficult for even the great intelligence of humans to override genetic predispositions. Head and heart unite more easily when new threats relate to earlier ones. When they do, then fears of those threats may develop easily, but often in unmodulated fashion. Excessive fears of dentists and of AIDS grow out of ancient fears of injury and of infection.

Two tales show how food aversion conditions more easily when a novel food is paired with nausea than with pain. The first is of biased learning. Seligman (1970) developed nausea and vomiting some hours after a meal that included his first tasting of bérnaise sauce. Despite knowing that his affliction was probably viral, he acquired a lasting aversion to béarnaise sauce. His 
learning overrode his logic. The second tale is of failure to condition. Marks developed intense epigastric pain but no nausea while eating catfish for the first time. After 14 hours of agony, intestinal obstruction from an intussuscepted Meckel's diverticulum was found and corrected. No aversion to catfish followed. Such conditioning of food aversion to nausea rather than pain makes evolutionary sense; gastrointestinal toxins give rise to nausea and vomiting more than to pain.

Parents have difficulty training their offspring to fear evolutionarily recent dangers. It is hard for parents to "shift (children's) attitudes toward fear of matches, knives, bottles, dangerous sports, and the like, or toward tolerance and affection for uncles, aunts, physicians, cod liver oil, green vegetables, keeping on mittens and the like. Progress is slow" (Thorndike 1935). Thorndike here describes prepotency and preparedness for both fear and attraction. Our nervous system is neither a tabula rasa nor a clockwork machine. In addition to built-in biases, it has flexibility; its preexisting pathways can be strengthened or weakened according to certain rules that make it able to fine-tune its responses to various environments.

\section{Benefits and Costs}

There is an interesting tradeoff between biases and flexibility. Biases allow swift response to old threats with a minimum of experience, but at the cost of false alarms to cues that no longer indicate danger. The lack of other biases also has costs: We adapt slowly to some evolutionarily recent dangers. Though we fear much that now carries little risk, we accept many new perils with equanimity. We have too much fear of spiders, but too little fear of driving fast, saturated fat, and very loud music.

Our brain's flexibility does help us to (slowly) learn anxiety to totally new dangers, but this carries the cost of frequent misconnections of anxiety to cues that do not signal danger. We make inappropriate connections, thrust meaning on random sequences, and develop superstitious fears. We make false correlations between events (Mineka and Tomarken 1989) and misattribute them. particularly when anxious. People who are poor judges of probability report more experiences of illusory causality (Blackmore 1990a,b).

\section{Cognitive Biases}

Our cognitive mechanisms seem to have built-in biases shaped by natural selection. These biases usually give the right answer in daily life, but they can go wrong in circumstances that were rare in our evolutionary past. We attend to and fear rare events more than common ones: a jumbo jet crash more than daily road deaths, a rare new syndrome more than heart disease (Tversky and Kahneman 1974). We undervalue base rates in calculating risk (Kahneman et al. 1982). We attend unduly to superficial similarities to the problem at hand (Nisbell and Russ 1980). We remember recent events more than those long 
past. We use accessible information that is unreliable rather than search for more valid data further afield. Abstract learning is more domain-specific than previously believed (Fodor 1983; Cosmides and Tooby 1987). This specificity is beneficial, because the possibilities for action are infinite. As Cosmides and Tooby (1987, p. 296) put it: "When a tiger bounds toward you, what should your response be? Should you file your toenails? Do a cartwheel? Sing a song? Is this the moment to run an uncountable number of randomly generated response possibilities through the decision rule? And again, how could you compute which possibility would result in more grandchildren? The alternative: Darwinian algorithms specialized for predator avoidance, that err on the side of false positives in predator detection, and, upon detecting a potential predator, constrain your responses to flight, fight or hiding." Emotions are good examples of domain-specific mechanisms. Anxiety evolved to deal efficiently with the domain of danger and its subtypes differentiated to avert specific threats within that domain.

\section{Implications for Research and Treatment}

Current anxiety research often seeks syndrome-specific neurophysiological defects. Although such defects undoubtedly exist for some patients with some syndromes, exclusive reliance on this approach leads to three difficulties. First, if anxiety is a normal defense, then some marked anxiety is likely to be, like being very tall, at the tail end of a Gaussian distribution. Different anxiety thresholds may often reflect, not specific defects, but individual polygenic variation similar to that which accounts for variation in susceptibility to cough, vomiting, or fever.

Second is the difficulty in neatly dividing anxiety disorders into mutually exclusive subtypes when each may in fact correspond to a particular danger but none is completely differentiated from any other. If this is correct, then attempts to delineate mutually exclusive anxiety disorders are likely to fail.

Third is the problem in deciding which physiological aspects of anxiety reflect abnormalities and which merely reflect normal operation of the anxiety system. The sites, pathways, and neurotransmitters that regulate anxiety, like those that regulate normal vomiting, are its cause only in the superficial sense of being part of a long mediating chain. Anxiolytic drugs may correct no primary defect but rather block defensive responses well downstream from the initiating problem. I ikewise, " $[\mathrm{B}]$ rain imaging data do not address the cause of OCD in any way whatsoever. ... [M]ental activity as well as motor behavior, regardless of 'cause,' is mediated by the biochemical processes of the brain. Brain imaging data merely provide clues to some of the sites of abnormal cerebral activity of complex mentation and behavioral patterns of [OCD]" (Baxter 1990).

"Pharmacological dissection" seeks to delineate specific syndromes on the basis of response to particular drugs. But a single drug, even one that affects only a specific brain system, can affect many etiologically diverse 
conditions. Just as the analgesic effects of aspirin are not a sound basis for classifying arthritis, so antidepressants do not help us classify the many. conditions in which they reduce dysphoria-anxiety, depression, schizophrenia, Alzheimer's disease, multiple sclerosis, and carcinoma. Current drugs for anxiety may be more like aspirin for pain than like insulin for juvenile-onset diabetes.

Exposure therapy is similarly nonspecific in its effects. Prolonged and repeated nontraumatic exposure to anxiety cues activates the evolved habituation mechanism that down-regulates fear. Without habituation to repeated stimulation, continual overresponding would prevent normal living. The lasting improvement from exposure therapy tells us little about how a phobia began but perhaps something about how avoidance maintains the established disorder.

\section{The Heuristic Value of an Evolutionary Perspective}

An evolutionary view can help explain otherwise puzzling features of anxiety by suggesting new and testable hypotheses about its function, and a search for relevant evidence. To take an example, stranger fear arises worldwide in infants at about six months of age. In trying to explain this, Marks when writing Fears, Phobias, and Rituals (1987) reasoned that a fear that is so transcultural is likely to be adaptive. At age six months, babies start to crawl away from mother and encounter strangers more often. Were strangers especially dangerous to infants in our recent evolutionary past? A search for relevant evidence found much that was emerging. Infanticide by strangers turned out to be so common that it is a strong selective force in primates as well as other species (Hrdy 1977). Abundant documentation also emerged that even today human infants are far more likely to be killed or abused by strangers than by familiars (Daly and Wilson 1989).

Without an evolutionary perspective the above hypothesis would not have been thought of and the evidence not have been sought. It was not a post hoc prediction; Marks did not know that such evidence was emerging at the time he began to look for it. Had infanticide turned out to be rare, the hypothesis would have been falsified.

Another new testable hypothesis arising out of an evolutionary view concerns agoraphobia. Mild "normal" agoraphobia seems homologous to fear of leaving the home range in territorial animals, a situation fraught with danger in the wild. Being away from home should thus be a prepotent cue for fear in normal young adults. An aversive event such as the hearing of repeated screams should evoke more anxiety (indicating prepotency) and condition more avoidance (showing preparedness) when it occurs in a public place far from, rather than near, home, even when familiarity has been controlled. Marks suggested this test to van den Hout; the results bore out the prediction (van den Hout, unpublished).

An evolutionary perspective might also explain why general anxiety is not 
always aversive and can even be pleasurable. Millions flock to be thrilled by horror movies, the big wheel, tightrope walkers, and the like. Perhaps this is a form of play behavior, like so many other enjoyable games that help us deal better with real problems when the time comes. Young mammals spend much time in play that teaches them the game of life (Smith 1982). Hypotheses to test this view should be formulable.

The four defensive strategies noted earlier-escape, aggression, freezing, and submission-are deployed to varying degrees in different subtypes of anxiety, in accordance with their utility. Examples include the greater prominence of nausea rather than anxiety in food phobias, and of syncope rather than flight in blood/injury phobias. Predictions yet to be tested include these hypotheses: (a) Submission is more marked in social than animal phobias, (b) freezing is more pronounced in fear of heights than of animals, and (c) flight is more pronounced in fear of animals than in fear of heights. Close matching of the features of anxiety subtypes to the threats they defend against demands the testing of many such predictions. This major research program is likely to reveal unsuspected facets of anxiety and its disorders.

\section{CONCLUSION}

The capacity for anxiety, like other normal defenses, has been shaped by natural selection. Anxiety disorders, like disorders of other defensive systems, are mainly disorders of regulation that entail excessive or deficient responses. As we steadily unravel the neurophysiology of the mediating mechanisms we need to remember that even if we knew every connection of every neuron, every action of every transmitter, our understanding would remain inadequate until we also knew the function for which those mechanisms were shaped. If we find drugs that offer reduction of anxiety without major side effects or dependency, then we will urgently need to know more about when anxiety is useful and when it is not. In the meantime, more knowledge about the adaptive significance of anxiety and its subtypes, and the normal mechanisms that regulate them, will help us make even more rapid progress in understanding and treating anxiety disorders.

Helena Cronin made many valuable criticisms of the manuscript, as did members of the Evolution and Psychiatry Project at the Department of Psychiatry at the University of Michigan.

\section{REFERENCES}

Ainsworth, M.D., Blehar, M.C., Waters, E., and Wall, S. Patterns of Attachment: A Psychological Study of the Strange Situation, Hillsdale, NJ: Erlbaum, 1978.

Alcock, J. Animal Behavior: An Evolutionary Approach, Sunderland, MA: Sinauer, 1989.

Alexander, R.D. The search for a general theory of behavior. Behavioral Science 20: 77-100, 1975.

Barkow, J., Cosmides, L., and Tooby, J. (Eds.) The Adapted Mind, New York: Oxford University Press, 1992. 
Baxter, L. Neuroimaging in obsessive compulsive disorder: seeking the mediating neuroanatomy. Obsessive Compulsive Disorder. 167-188, 1990.

Berthenthal, B.I., Campos, J.J., and Caplovitz, K.S. Self-produced locomotion: an organizer of emotional, cognitive, and social development in infancy. In Continuities and Discontinuities in Development, R.M. Emde and Harmon, R. (Eds.). New York: Plenum, 1983.

Blackmore, S. Living in a nonrandom world. The Guardian. London, 1990a.

Blackmore, S. The lure of the paranormal. New Scientist. 62-69, $1990 \mathrm{~b}$.

Bowlby, J. Separation: Anxiety and Anger, New York: Basic Books, Inc, 1973.

Cannon, W.B. Bodily Changes in Pain. Hunger, Fear, and Rage: Researches into the Function of Emotional Excitement, New York: Harper and Row, 1929.

Cook, E.W., Hodes, R.L., and Lang, P.J. Preparedness and phobia: effects of stimulus content on human visceral conditioning. Journal of Abnormal Psychology 95(3): 195-207, 1986

Cosmides, L., and Tooby, J. From evolution to behavior: evolutionary psychology as the missing link. In The Latest on the Best: Essays on Evolution and Optimality, J. Dupre (Ed.). Cambridge, MA: MIT Press, 1987.

Daly, M. and Wilson, M. Homicide, New York: Aldine, 1989.

Darwin, C. The Expression of the Emotions in Man and Animals, Chicago: University of Chicago Press, 1965 [1872].

DuPont, H.L., and Hornick, R.B. Adverse effect of Lomotil therapy in shigellosis. Journal of the American Medical Association 226: 1525-1528, 1973.

Edmunds, M. Defence in Animals, Harlow, Essex, England: Longman, 1974.

Fodor, J. Modularity of Mind, Cambridge, MA: MIT Press, 1983.

Gelder, M.G., and Marks, I.M. Transsexualism and faradic stimulation. In Transsexualism and Sex Reassignment, R. Green (Ed.). Baltimore, MD: Johns Hopkins University Press, 1970.

Hart, B.L. Behavioral adaptations to pathogens and parasites: five strategies. Neuroscience and Biobehavioral Reviews 14: 273-294, 1990.

Howard, J.C. Disease and evolution. Nature 352; 565-567, 1991.

Hrdy, S.B. Infanticide as a primate reproductive strategy. American Scientist 65: 40-49, 1977.

James, W. The Principles of Psychology, New York: Holt, 1893.

Janzen, D.H. Evolutionary physiology of personal defense. In Physiological Ecology: An Evolutionary Approach io Resource Use, C.R. Townsend and P. Calow (Eds.). Oxford: Blackwell, 1981, pp. 145-164.

Kahneman, D., Slovic, P. and Tversky, A. Judgment Under Uncertainty: Heuristics and Biases, Cambridge: Cambridge University Press, 1982.

Kendler, K.S., Neale, M.C., et al. The genetic epidemiology of phobias in women: the interrelationship of agoraphobia, social phobia, situational phobia, and simple phobia. Archives of General Psychiatry 49: 273-281, 1992.

Klein, D.F. Anxiety Reconceptualized, New York: Raven Press, 1981.

Konner, M. Why the Reckless Survive, London: Penguin, 1990.

Krebs, J., and Davies, N. Behavioral Ecology: An Evolutionary Approach, Oxford: Blackwell, 1991.

Krebs, J.R. and Dawkins, R.D. Animal signals: mind-reading and manipulation. In Behavioral Ecology: An Evolutionary Approach, J.R. Krebs and N.B. Davies (Eds.). Sunderland, MA: Sinauer, 1984, pp. 380-402.

Lelliott, P., Marks, I., McNamee, G., and Tobena, A. Onset of panic disorder with agoraphobia: toward an integrated model. Archives of General Psychiatry 46(11):1000-1004, 1989.

Marks, I.M. Fears and Phobias. New York Academic Press, 1969.

Marks, I.M. Fears, Phobias, and Rituals, New York: Oxford University Press, 1987.

Marks, I.M. Blood-injury phobia: a review. American Journal of Psychiatry 145(10): 1207-1213, 1988.

Mayr, E. Teleological and teleonomic, a new analysis. Boston Stud. Philo. Sci. 14: 91-117, 1974.

Mineka, S., Davidson, M., Cook, M., and Keir, R. Observational conditioning of snake fear in rhesus monkeys. Journal of Abnormal Psychology 93: 355-372, 1984.

Mineka, S., Keir, R., and Price, V. Fear of snakes in wild and laboratory-reared rhesus monkeys (Macaca mulatta). Anim. Lrn. Behav. 8(4): 653-663, 1980.

Mineka, S., and Tomarken, A. The role of cognitive biases in the origins and maintenance of fear and anxiety disorders. In Aversion, Avoidance, and Anxiety: Perspectives on Aversely Motivated Behavior, L. Nilsson and T. Archer (Eds.), Hillsdale, NJ: Erlbaum, 1989. 
Nesse, R.M. An evolutionary perspective on panic disorder and agoraphobia. Ethology and Sociobiology 8: 73S-83S, 1987.

Nesse, R.M. Evolutionary explanations of emotions. Human Nature 1(3): 261-289, 1990a.

Nesse, R.M. The evolutionary functions of repression and the ego defenses. Journal of the American Academy of Psychoanalysis 18(2): 260-285, 1990b.

Nisbett, R., and Ross, L. Human Inference: Strategies and Shortcomings of Social Judgment, Englewood Cliffs, NJ: Prentice-Hall, Inc., 1980.

Öhman, A., and Dimberg, U. An evolutionary perspective on human social behavior. In Sociopsychology, W.M. Waid (Ed.). New York: Springer, 1984.

Paley, W. Natural Theology, Westmead, England: Gregg International Publications, 1970 [1802].

Plutchik, R. and Kellerman, H. Theories of Emotion, Orlando: Academic Press, Inc., 1980.

Ruse, M. Philosophy of Biology Today, Alhany, NY: State University of New York, 1988.

Scarr, S., and Salapatek, P. Patterns of fear development during infancy. Merrill-Palmer Quarterly 16: 53-90, 1970.

Seligman, M. On the generality of the laws of learning. Psychological Review 77: 406-418, 1970.

Smith, P.K. Does play matter? The functional and evolutionary aspects of animal and human play. Behavioral \& Brain Sciences 5: 139-184, 1982.

Stevens, K.M. Pain: evolutionary background and primary stimulus. Medical Hypotheses 7: 51-54, 1981.

Thorndike, E.L. The Psychology of Wants, Interests, and Attitudes, London: Appleton-Century, 1935 ,

Toft, C.A., Aeschlimann, A., and Bolis, L. (Eds.) Parasite-Host Associations: Coexistence or Conflict? New York: Oxford University Press, 1991.

Tversky, A., and Kahneman, D. Heuristics and biases. Science 185: 1124-1131, 1974.

vanden Hout, M. Agoraphobia: an extraterritorial fear. Unpublished manuscript.

Wilks C.G.W., and Marks, I.M. Reducing hypersensitive gagging. British Dental Journal 155: $263-265,1983$. 